\title{
The Relationship between Injury and Socioeconomic Status in Reference to the Fourth Korean National Health and Nutrition Examination Survey
}

Sung-Kyung Kim ${ }^{1 *}$, Hyocher Kim ${ }^{2}$ Kyungsuk Lee ${ }^{2}$, Hee-Tae Kang ${ }^{1}$, Sung-Soo Oh¹ and Sang Baek Ko ${ }^{1 *}$

\begin{abstract}
Objectives: This study aims to investigate the relationship between the total injury experience rate and socioeconomic status based on the fourth Korea National Health and Nutrition Examination Survey (KNHANES).

Methods: By analyzing data from the fourth KNHANES conducted from 2007 to 2009, we estimated the injury experience rate according to socioeconomic status, including the occupational characteristics of 11,837 subjects. Setting the injury experience rate as a dependent variable and socioeconomic status as an independent variable, we performed logistic regression to calculate odds ratios reflecting the likelihood of injury according to socioeconomic status while controlling for relevant covariates.

Results: In 797 subjects who had injury experience over the past 1 year, 290 persons (36.4\%) had a work-related injury. As their income, home value, and educational status increased, their injury experiences decreased. Among occupational groups, the craft, equipment, machine operating, and assembling workers showed the highest rate (10.6\%) of injury experience, and the lowest rate (5.7\%) was found in the unemployed group. After adjusting for the confounding variables, the experience of injury was significantly related to several socioeconomic factors: high income ( $\mathrm{OR}=0.54 ; 95 \% \mathrm{Cl}$ : 0.34-0.86), high home value ( $\mathrm{OR}=0.65 ; 95 \% \mathrm{Cl}: 0.43-0.96)$, low education status $(\mathrm{OR}=1.28 ; 95 \% \mathrm{Cl}: 1.07-1.52)$, and specific occupations such as craft, equipment, machine operating, and assembling work $(\mathrm{OR}=1.99 ; 95 \% \mathrm{Cl}: 1.60-2.47)$, skilled agriculture, forestry and fishery work (OR=1.43; 95\% Cl: 1.02-2.01), and simple labor $(\mathrm{OR}=1.38 ; 95 \% \mathrm{Cl}: 1.04-1.82)$.

Conclusions: The injury experience rate differed depending on the socioeconomic status. A negative correlation was found between the injury experience rate and income, low home value, and education level. Moreover, a higher rate of injury experience was found in occupation groups and physical worker groups in comparison to the unemployed group and white-collar worker groups. This study would be useful in selecting appropriate priorities for injury management in Korea.
\end{abstract}

Keywords: Injury, Socioeconomic status, Income, Occupation, Education

\footnotetext{
*Correspondence: stacte@yonsei.ac.kr; kohhj@yonsei.ac.kr

'Department of Occupational and Environmental Medicine, Wonju Severance

Christian's Hospital, Yonsei University, Wonju, Korea

Full list of author information is available at the end of the article
} 


\section{Introduction}

Injury is an important health issue [1,2]. Injury is a major contributor to morbidity, disability, and even early mortality; unexpected death that shortens life expectancy further results in increased social loss and economic costs [3]. According to a report from the World Health Organization, about 5 million people, 83.7 per 100,000 , worldwide died due to injuries in 2000. This accounts for $9 \%$ of global mortality, and the cost for treating them totaled about $12 \%$ of all medical costs worldwide [4]. Thus despite the major health impact of injury, it has drawn relatively little attention among health-related concerns [5]. The situation is particularly serious in the Republic of Korea. According to OECD health data published in 2007, Korea had the second highest rate of injury associated fatalities (67.5 per 100,000 ) among OECD countries in 2004. This number accounted for $12.4 \%$ of all mortalities in Korea that year, and this proportion was the highest among OECD nations [6]. As injury mechanisms have been analyzed and comprehended, perceptions about injury have now shifted from seeing them as the consequences of random and unavoidable accidents to preventable accidents in most cases. In accordance with this changed appreciation about injury, several countries have been collecting data related to injuries for analysis purposes in order to develop effective policies to prevent further injuries [7].

Injuries can be categorized into fatal and nonfatal injuries. A fatal injury is defined as death resulting from the combination of all injuries sustained, and a nonfatal injury is an acute impact, short of death, on one's health from an external force or agent [8]. The causes of both fatal and nonfatal injuries are known to vary by age and sex [8]; exposure to mechanochemical agents, unsafe work environment or activities $[9,10]$, and stress and individual physiological characteristics [10-12] have been noted to be sources of injury. In addition, social surroundings, including physical and socioeconomic factors, are also considered to contribute to injury [13]. Haddon's matrix describes injury as the result of interaction among a person, a causative agent, and the external environment [14]. Socioeconomic status represents the relative social position of an individual or a group that is determined by income, occupation, assets, level of education, and similar factors, and it is known to affect both individuals and external environmental factors within Haddon's matrix $[15,16]$. Thus, the importance of socioeconomic factors to injury must not be underestimated. Although injury is related to level of income, occupation type, job status, and other socioeconomic factors, a limited number of studies in Korea have dealt with injury in relation to socioeconomic status. One study reported a higher incidence of injury in groups with low education levels, certain vocations that are vulnerable to injury, and low income $[17,18]$. Another study reported that people with higher income levels and city-dwellers had a significantly smaller proportion of injury than those with a low income or who resided in rural areas, respectively, within a given population group [7].

This study is based on data from the fourth Korea National Health and Nutrition Examination Survey (KNHANES), which contains questions for identifying the incidence of injury and accidents in workers, along with their socioeconomic and occupational characteristics. We analyzed the data to identify various characteristics of injury according to socioeconomic status and to confirm the relationship between the incidence of injury and socioeconomic level.

\section{Materials and methods}

\section{Study subjects}

The fourth KNHANES was conducted for 3 years from 2007 to 2009, and 23,632 (74.5\%) out of 31,705 individuals sampled participated in the study [19]. Among them, 11,837 people between 20 and 59 years old who reported having sustained an injury within the past 1 year were selected for final analysis.

\section{Study methods}

This study defined personal injury as experience of injury within the past 1 year at the time of answering the KNHANES questionnaire. Persons who reported having sustained an injury within the past 1 year were stated to have an experience of injury, and among them, injuries originating from working were noted as occupational injuries [20].

The population characteristics of age, sex, and marital status were obtained, and information on socioeconomic characteristics such as annual household income, home value, and educational level, occupation, type of employment, national basic livelihood security status, and job status were also collected. We organized the occupations into 7 groups according to the major categorizations of the 6th Korean Standard Classification of Occupations: 'manager, professional, and administrator', 'clerk', 'service and sales worker', 'skilled agricultural, forestry, and fishery worker', 'craft, equipment, machine operating, and assembling worker', 'elementary worker', and 'unemployed'. For the type of employment, they were divided into salaried workers, self-employed, and unpaid family workers. The salaried workers were further divided into fully employed, temporary, and day workers. Finally, the type was also divided into full-time and part-time jobs according to time spent at work.

In this study, the proportions of people with injury experience among all questionnaire responders were calculated in accordance with each of the following 
socioeconomic factors: annual household income, type of employment, sex, age, level of education, national basic livelihood security status, home ownership, home value, and marital status. Experience with injury was set as a dependent variable, and annual household income, home ownership, education level, and type of occupation were designated as independent variables. Age, sex, and marital status were adjusted as confounding variables, and multiple logistic regression analysis was performed to compute the adjusted odds ratio and 95\% confidence interval of the sample group. Statistical evaluation was done with SAS software version 9.2 (SAS Inc., Cary, NC, USA), and statistical significance was determined to be below 0.05 .

\section{Results}

Socioeconomic and general demographic characteristics of study subjects

There were 5,047 males (42.6\%) and 6,790 females (57.4\%). Distribution by age groups showed that 2,097 subjects (17.7\%) were in their 20s, 3,470 (29.3\%) in their 30 s, 3,386 (28.6\%) in their 40s, and 2,884 (24.4\%) in their 50 s. With regard to marital status, 2,134 subjects (18.1\%) stated that they had never been married, while 9,018 (76.5\%) subjects reported being married; 244 subjects $(2.1 \%)$ reported being bereaved, and 400 subjects (3.4\%), divorced. Among the subjects, 225 (2.0\%) had an annual household income of less than 5 million won ( 1 million Korean won is approximately US\$1,000), and this group had the smallest number of subjects. The group with an annual household income between 20 million and 50 million won had the largest number of members, 5,711 (51.8\%). Those who were on national basic livelihood security numbered 323 subjects (2.7\%), while 11472 subjects (97.6\%) were covered by National Health Insurance. There were 3,899 people $(33.0 \%)$ who did not own a house, 6,708 (56.8\%) owned a house, and 1,203 subjects (10.2\%) owned two or more houses. Among home values, the largest number of subjects, 2,120 (28.2\%), owned homes ranging between 100 million and 200 million won (approximately \$US100,000200,000). The group with a middle school diploma had the smallest number of subjects, $1,282(10.8 \%)$, while the largest number of subjects, 5,124 (43.2\%), had a high school diploma but no additional degrees. There were 610 subjects $(5.5 \%)$ in the 'skilled agricultural, forestry, and fishery worker' occupational group, which had the fewest subjects. The service and sales worker group had the largest number of subjects, 1,886 (17.1\%). The unemployed group contained 3,163 subjects $(28.8 \%)$. When asked about type of employment, 5,064 subjects (64.1\%) responded that they were salaried workers, while 2,384 people (30.2\%) were self-employed. When the salaried workers were further subdivided, there were 845 subjects
(16.8\%) who listed their jobs as temporary, and 547 subjects $(10.9 \%)$ reporting being day workers. Full-time workers numbered 4,216 (84.2\%), and there were 792 part-time workers (15.8\%) (Table 1).

Injury Characteristics There were 797 subjects (6.7\%) who had sustained an injury in the previous 1 year at the time of answering the questionnaire. Among them, 290 subjects (36.4\%) incurred their injuries while working. When the injury mechanisms were studied in all of the injured persons, transportation accidents accounted for the most subjects, 296 (37.4\%). The remaining injuries were 150 slips (19.0\%), 115 collisions (14.5\%), 76 falls (9.6\%), 38 stabs/amputations (4.8\%), 33 cases of intoxication (4.2\%), 21 machinery accidents $(2.7 \%), 15$ lacerations (1.9\%), and 8 burn wounds (1.0\%).

The subjects were also classified according to the type of health care facility where they had received their initial treatment. The emergency room was visited by 170 (21.8\%), and 356 subjects (45.6\%) underwent treatment at an outpatient clinic. Those who were admitted to a hospital due to their injuries numbered 255 (32.7\%). There were 722 subjects (99\%) whose injuries were nonintentional accidents. Self-injuries with the intention to self-harm were noted in 5 subjects $(0.6 \%)$, and injuries incurred due to violence from others were reported by 3 people $(0.4 \%)$ (Table 2$)$.

\section{Injury incidence according to socioeconomic level and general demographic characteristics}

The males $(8.4 \%)$ had a higher incidence of injury than the females (5.5\%). Those in their 20s (7.4\%) and 50s (7.4\%) showed a higher incidence of injury experience than people in their $30 \mathrm{~s}$ (6.2\%) and 40s (6.3\%). Those who reported being married (6.4\%) showed a lower injury incidence than divorced subjects (10.5\%). Among the subjects who earned an annual income of less than 5 million won, $10.7 \%$ of the subjects had experienced an injury, which was the highest incidence among the income levels. The incidence became smaller with increasing annual income. Although there was no statistical significance, those on national basic livelihood security had a slightly higher injury incidence (8.1\%) than those not using this support program. Those on Medical Aid had a higher injury incidence $(7.9 \%)$ than those on National Health Insurance. The group that owned one or more homes showed a lower incidence of injury (6.5\%) than the group without home ownership. Subjects who owned a home valued below 50 million won reported the highest injury incidence, at $7.2 \%$, and those whose home value was above 500 million won had a $4.7 \%$ injury incidence, showing a lower risk of injury in people with a higher home value. People who had an educational level of elementary school or below had an injury incidence of $8.2 \%$ showing a lower risk of injury 
Table 1 Demographic and socioeconomic characteristics of the subjects

\begin{tabular}{|c|c|c|}
\hline Variables & Categories & Number (\%) \\
\hline \multirow[t]{2}{*}{ Sex } & Male & $5,047(42.6)$ \\
\hline & Female & $6,790(57.4)$ \\
\hline \multirow[t]{4}{*}{ Age (years old) } & $20-29$ & 2,097 (17.7) \\
\hline & $30-39$ & $3,470(29.3)$ \\
\hline & $40-49$ & 3,386 (28.6) \\
\hline & $50-59$ & $2,884(24.4)$ \\
\hline \multirow[t]{4}{*}{ Marital status } & Married & $9,018(76.5)$ \\
\hline & Bereaved & $244(2.1)$ \\
\hline & Divorced & $400(3.4)$ \\
\hline & Never married & $2,134(18.1)$ \\
\hline $\begin{array}{l}\text { Household } \\
\text { income per year }\end{array}$ & $<5$ & $225(2.0)$ \\
\hline \multirow[t]{4}{*}{ (1 million KRW) } & $5-<10$ & $586(5.3)$ \\
\hline & $10-<20$ & $1,795(16.3)$ \\
\hline & $20-<50$ & $5,711(51.8)$ \\
\hline & $\geq 50$ & $2,712(24.6)$ \\
\hline \multirow{3}{*}{$\begin{array}{l}\text { National basic } \\
\text { livelihood security }\end{array}$} & Current recipient & $323(2.7)$ \\
\hline & Former recipient & $284(2.4)$ \\
\hline & Non-recipient & $11,203(94.9)$ \\
\hline \multirow[t]{2}{*}{ Health insurance } & National health insurance & $11,472(97.6)$ \\
\hline & Medical aid & $279(2.4)$ \\
\hline \multirow[t]{3}{*}{ Home ownership } & No home & $3,899(33.0)$ \\
\hline & 1 home & $6,708(56.8)$ \\
\hline & More than 1 home & $1,203(10.2)$ \\
\hline \multirow{5}{*}{$\begin{array}{l}\text { Home value } \\
\text { (x } 1 \text { million KRW) }\end{array}$} & $<50$ & $925(12.3)$ \\
\hline & $50-<100$ & $1,494(19.9)$ \\
\hline & $100-<200$ & $2,120(28.2)$ \\
\hline & $200-<500$ & $2,084(27.7)$ \\
\hline & $\geq 500$ & $898(11.9)$ \\
\hline \multirow[t]{4}{*}{ Education } & $\leq$ Elementary & $1,382(11.7)$ \\
\hline & Middle & $1,282(10.8)$ \\
\hline & High & $5,124(43.2)$ \\
\hline & $\geq$ University & $4,041(34.2)$ \\
\hline \multirow[t]{7}{*}{ Occupation } & $\begin{array}{l}\text { Manager, professional, } \\
\text { and administrators }\end{array}$ & $1,800(16.4)$ \\
\hline & Clerks & $1,179(10.7)$ \\
\hline & Service and sales workers & $1,886(17.1)$ \\
\hline & $\begin{array}{l}\text { Skilled agricultural, forestry, } \\
\text { and fishery workers }\end{array}$ & $610(5.5)$ \\
\hline & $\begin{array}{l}\text { Craft, equipment, machine } \\
\text { operating, and assembling } \\
\text { workers }\end{array}$ & $1,413(12.8)$ \\
\hline & Elementary workers & $950(8.6)$ \\
\hline & Unemployed $^{\dagger}$ & $3,163(28.8)$ \\
\hline
\end{tabular}

Table 1 Demographic and socioeconomic characteristics of the subjects (Continued)

\begin{tabular}{lll}
\hline Employment type & Salaried workers & $5,064(64.1)$ \\
& Self-employed & $2,384(30.2)$ \\
& Family business without pay & $456(5.8)$ \\
Status of salaried & Fully employed & $3,636(72.3)$ \\
workers & & \\
& Temporary & $845(16.8)$ \\
& Day worker & $547(10.9)$ \\
Working hours & Full-time & $4,216(84.2)$ \\
& Part-time & $792(15.8)$ \\
\hline${ }_{\text {including homemakers and students. }}$
\end{tabular}

in people with a higher educational level. When the incidence of injury was analyzed by type of employment, the 'craft, equipment, machine operating, and assembling worker' group had the most injured members, at $10.6 \%$. Next was 'skilled agricultural, forestry, and fishery workers', among whom $7.7 \%$ were injured. 'Elementary workers' $(7.5 \%)$ had the third highest incidence of injury. Those who reported being unemployed at the time of the survey had the lowest proportion (5.7\%) of injury. Type of employment did not show any statistical significance in relation to injury incidence, but the incidence was found to be higher in salaried workers $(7.4 \%)$, day workers (8.0\%), and full-time workers (7.5\%) (Table 3).

Rates of emergency room visits and hospital admissions in terms of income level, home value, education, and type of job

Although no statistical significance was shown, those with a lower income level had a higher frequency of visits to an outpatient clinic or emergency room when injured. In the group with an annual household income of less than 5 million won, $5.8 \%$ had visited an outpatient clinic or emergency room, and $4.3 \%$ of the group with an annual income of more than 50 million won had paid a visit to an outpatient clinic or emergency room. According to the value of one's home, no statistical difference was found among the groups, but the incidence was lowest in the group with a home valued at more than 500 million won (3.2\%). Furthermore, people with a lower educational level had injuries that required medical attention in an outpatient setting or emergency room. Specifically, among the people with an elementary school education or less, $5.2 \%$ visited a medical institution for their injuries, and among those with a university education or higher, the visit rate was $3.8 \%$. By type of occupation, 'craft, equipment, machine operating, and assembling workers' had the highest incidence of injury that required professional medical assistance at a clinic or emergency room, at 6.7\%; 'elementary workers' had an incidence of $5.4 \%$ and 'skilled agricultural, forestry, 
Table 2 Characteristics of injury

\begin{tabular}{lll}
\hline Variables & Categories & Number (\%) \\
\hline Any injury & No & $11,040(93.3)$ \\
Occupational injury & No & $797(6.7)$ \\
& Yes & $11,547(97.6)$ \\
Proportion of occupational & No & $290(2.4)$ \\
injuries among all injuries & & $507(63.6)$ \\
& Yes & \\
Nature of injury & Transport accident & $290(36.4)$ \\
& Fall & $76(9.6)$ \\
& Slip & $150(19.0)$ \\
& Collision & $115(14.5)$ \\
& Laceration & $15(1.9)$ \\
& Stab/amputation & $38(4.8)$ \\
& Machinery accident & $21(2.7)$ \\
& Burn & $8(1.0)$ \\
Injury intention & Poisoning & $33(4.2)$ \\
& Others & $39(4.9)$ \\
Treatment type & Emergency room & $170(21.8)$ \\
& Ambulatory care & $356(45.6)$ \\
& Hospital admission & $255(32.7)$ \\
& Unexpected accident & $772(99.0)$ \\
& Intentional self-injury & $5(0.6)$ \\
& Violence by other people & $3(0.4)$ \\
\hline
\end{tabular}

fishery workers' had an incidence of 5.3\%. The 'manager, professional, and administrator' group and unemployed group each had an incidence of $4.1 \%$ requiring medical assistance (Table 4).

Those with a lower income level also had a higher hospital admission rate. The group earning less than 5 million won had an admission rate of $5.8 \%$, while the rate was $4.3 \%$ for the group with an annual income of more than 5 million won. The group with a home value of more than 500 million won showed the lowest rate $(1.5 \%)$ of admission, but the difference by home value was not statistically significant. Regarding education, people with an elementary school diploma or less had a $3.0 \%$ admission rate, which was significantly higher than the $1.8 \%$ admission rate found in the group with a university diploma or higher. The 'craft, equipment, machine operating and assembling worker' group had the highest admission rate, at $3.9 \%$, and next was the 'skilled agricultural, forestry, and fishery workers', who had a $2.8 \%$ admission rate. The admission rate for the service and sales group was $1.6 \%$ (Table 5 ).
Relation of injury to income level, home value, education, and type of occupation

After multiple logistic regression analysis, the odds ratio between the injury incidence and income groups decreased with increasing annual income. The odds ratios for the groups with an income between 20 million and 50 million won and an income of 50 million won or more relative to the group with an annual income of 5 million won or less were 0.6 (95\% C.I.: 0.38-0.93) and 0.54 (95\% C.I.: 0.34-0.86), respectively. According to an analysis by home value, the odds ratio became smaller as the home value increased above the reference group with homes valued at less than 50 million won. However, the reduction in odds ratios did not have statistical significance except for the group with a home value of more than 500 million won (OR: 0.65, 95\% C.I.: 0.430.96). With a low level of education, the injury odds ratio increased. When compared to people with an educational level of university or higher, those who had graduated from high school or below showed a 1.28 times (95\% C.I.: 1.07-1.52) higher risk of injury, and the odd ratios for the groups with a middle school diploma and with an elementary school diploma were 1.57 (95\% C.I.: 1.20-2.05) and 1.89 (95\% C.I.: 1.44-2.48), respectively. By type of job category, the 'craft, equipment, machine operating, and assembling workers' had an odds ratio of 1.99 (95\% C.I.: 1.60-2.47) relative to the unemployed individuals. 'Skilled agricultural, forestry, and fishery workers' had an odds ratio of 1.43 (95\% C.I.: 1.02-2.01), and 'elementary workers' had an odds ratio of 1.38 (95\% C.I.: 1.04-1.82) (Table 6).

\section{Discussion}

This study determined the total occurrence of injuries in the general population of Korea and the incidence of occupationally related injury using answers related to injury from the KNHANES questionnaire and analyzed its association with socioeconomic factors. The proportion of subjects who sustained at least 1 injury in the 1-year period previous to the survey was $6.7 \%$, and among the injured subjects, $2.4 \%$ were work-related injuries. Occupational injury accounted for $36.4 \%$ of all the reported injuries. In the Korean Working Conditions Survey sponsored by the Korean Department of Labor in 2006, 2010, and 2011, the average injury rate was $2.4 \%$. The rate of occupational injury was $2 \%$, and workplace injuries accounted for $84 \%$ of all the injuries received. A similar survey of $27 \mathrm{EU}$ nations in 2005 revealed a mean injury rate of $9.1 \%(3.7 \%-21.5 \%)$ [21]. In the present study, the occupational injury rate was $2.4 \%$, which was similar to the findings of the Korean Working Conditions Survey, but lower than the European average.

In previous studies, it was found that each increased level of socioeconomic status shows a better health 
Table 3 Number of subjects who experienced injury by socioeconomic status

\begin{tabular}{|c|c|c|c|c|}
\hline \multirow[t]{2}{*}{ Variables } & \multirow[t]{2}{*}{ Categories } & \multicolumn{2}{|c|}{ Number (\%) } & \multirow[t]{2}{*}{ p value $*$} \\
\hline & & Yes & No & \\
\hline \multirow[t]{2}{*}{ Sex } & Male & $422(8.4)$ & $4,625(91.6)$ & $<.0001$ \\
\hline & Female & $375(5.5)$ & $6,415(94.5)$ & \\
\hline \multirow[t]{4}{*}{ Age (year) } & $20-29$ & $156(7.4)$ & $1,941(92.6)$ & 0.100 \\
\hline & $30-39$ & $215(6.2)$ & $3,255(93.8)$ & \\
\hline & $40-49$ & $213(6.3)$ & $3,173(93.7)$ & \\
\hline & $50-59$ & $213(7.4)$ & $2,671(92.6)$ & \\
\hline \multirow[t]{4}{*}{ Marital status } & Married & $580(6.4)$ & $8,438(93.6)$ & 0.008 \\
\hline & Bereaved & $19(7.8)$ & $225(92.2)$ & \\
\hline & Divorces & $42(10.5)$ & $358(89.5)$ & \\
\hline & Never married & $156(7.3)$ & $1,978(92.7)$ & \\
\hline Household income per year & $<5$ & $24(10.7)$ & $201(89.3)$ & 0.020 \\
\hline \multirow[t]{4}{*}{ (1 million KRW) } & $5-<10$ & $52(8.9)$ & $534(91.1)$ & \\
\hline & $10-<20$ & $126(7.0)$ & $1,669(93.0)$ & \\
\hline & $20-<50$ & $385(6.7)$ & $5,326(93.3)$ & \\
\hline & $\geq 50$ & $167(6.2)$ & 2,545 (93.8) & \\
\hline \multirow[t]{3}{*}{ National basic livelihood security } & Current recipient & $26(8.1)$ & $297(92.0)$ & 0.619 \\
\hline & Former recipient & $20(7.0)$ & $264(93.0)$ & \\
\hline & Non-recipient & $750(6.7)$ & $10,453(93.3)$ & \\
\hline \multirow[t]{2}{*}{ Health insurance } & National health insurance & $771(6.7)$ & $10,701(93.3)$ & 0.444 \\
\hline & Medical aid & $22(7.9)$ & $257(92.1)$ & \\
\hline \multirow[t]{2}{*}{ Home ownership } & No & $279(7.2)$ & $3,620(92.8)$ & 0.206 \\
\hline & Yes & $517(6.5)$ & $7,394(93.5)$ & \\
\hline \multirow[t]{5}{*}{ Home value (1 million KRW) } & $<50$ & $67(7.2)$ & $858(92.8)$ & 0.047 \\
\hline & $50-<100$ & $116(7.8)$ & $1,378(92.2)$ & \\
\hline & $100-<200$ & $139(6.6)$ & $1,981(93.4)$ & \\
\hline & $200-<500$ & $131(6.3)$ & $1,953(93.7)$ & \\
\hline & $\geq 500$ & $42(4.7)$ & $856(95.3)$ & \\
\hline \multirow[t]{4}{*}{ Education } & sElementary & $114(8.2)$ & $1,268(91.8)$ & 0.004 \\
\hline & Middle & $96(7.5)$ & $1,186(92.5)$ & \\
\hline & High & $355(6.9)$ & $4,769(93.1)$ & \\
\hline & $\geq$ University & $230(5.7)$ & $3,811(94.3)$ & \\
\hline \multirow[t]{7}{*}{ Occupation } & Manager, professional, and administrators & $108(6.0)$ & $1,692(94.0)$ & $<.0001$ \\
\hline & Clerks & $79(6.7)$ & $1,100(93.3)$ & \\
\hline & Service and sales workers & $114(6.1)$ & $1,772(93.9)$ & \\
\hline & Skilled agricultural, forestry, and fishery workers & $47(7.7)$ & $563(92.3)$ & \\
\hline & Craft, equipment, machine operating, and assembling workers & $150(10.6)$ & $1,263(89.4)$ & \\
\hline & Elementary workers & $71(7.5)$ & $879(92.5)$ & \\
\hline & Unemployedt & $194(5.7)$ & $2,969(94.3)$ & \\
\hline \multirow[t]{2}{*}{ Employment type } & Salaried workers & $376(7.4)$ & $4,688(92.6)$ & 0.232 \\
\hline & Self-employed & $175(7.3)$ & $2,209(92.7)$ & \\
\hline
\end{tabular}


Table 3 Number of subjects who experienced injury by socioeconomic status (Continued)

\begin{tabular}{|c|c|c|c|c|}
\hline & Family business without pay & $24(5.3)$ & $432(94.7)$ & \\
\hline \multirow[t]{3}{*}{ Status of salaried workers } & Fully employed & $275(7.6)$ & $3,361(92.4)$ & 0.423 \\
\hline & Temporary & $54(6.4)$ & $791(93.6)$ & \\
\hline & Day workers & $44(8.0)$ & $503(92.0)$ & \\
\hline \multirow[t]{2}{*}{ Working hours } & Full-time & $317(7.5)$ & $3,899(92.5)$ & 0.414 \\
\hline & Part-time & $53(6.7)$ & $739(93.3)$ & \\
\hline
\end{tabular}

*p value by chi-squared test.

tincluding homemakers and students.

status than the level below it in a dose-response relationship [22], and this socioeconomic gradient is evident in both fatal [23-34] and non-fatal injuries [26,28,35-40]. We found the same in our study. As the levels of income and education increased, the injury incidence was reduced. The group with an annual income of more than 50 million won had an odds ratio of 0.54 (95\% C.I.: 0.340.86) relative to the group with an income of less than 5 million won, and the group with a home valued at more than 500 million won had an odds ratio of 0.65 (95\% C.I.: 0.43-0.96) compared to the group with a home valued at less than 50 million won. People with an elementary school education or below had an odds ratio of
1.89 (95\% C.I.: $1.44-2.48)$ relative to those with a university or higher education. The injury rates that required a visit to an outpatient clinic and emergency room (Table 5) and that needed hospital admission were also higher in vulnerable socioeconomic groups who earned low income, had less education, owned a less expensive home, and worked in elementary labor. The results of our study were in accord with 2 previous studies.

The type of occupation and job status can also be factored in to consider the socioeconomic status [17]. The 'craft, equipment, machine operating, and assembling worker' group had the highest injury incidence of $10.6 \%$ among all of the occupational groups. 'Skilled

Table 4 Rate of emergency room or ambulatory care visits among those who experienced injury

\begin{tabular}{|c|c|c|c|c|}
\hline \multirow[t]{2}{*}{ Variables } & \multirow[t]{2}{*}{ Categories } & \multicolumn{2}{|c|}{ Number (\%) } & \multirow[t]{2}{*}{$p$ value* } \\
\hline & & Yes & No & \\
\hline Household income per year & $<5$ & $13(5.8)$ & $212(94.2)$ & 0.1801 \\
\hline \multirow[t]{4}{*}{ (1 million KRW) } & $5-<10$ & $38(6.5)$ & $548(93.5)$ & \\
\hline & $10-<20$ & $79(4.4)$ & $1716(95.6)$ & \\
\hline & $20-<50$ & $257(4.5)$ & $5454(95.5)$ & \\
\hline & $\geq 50$ & $117(4.3)$ & 2595 (95.7) & \\
\hline Home value & $<50$ & $40(4.3)$ & $885(95.7)$ & 0.474 \\
\hline \multirow[t]{4}{*}{ (1 million KRW) } & $50-<100$ & $71(4.5)$ & $1,423(95.5)$ & \\
\hline & $100-<200$ & $96(4.8)$ & $2,024(95.3)$ & \\
\hline & $200-<500$ & $94(4.5)$ & $1,990(95.5)$ & \\
\hline & $\geq 500$ & $29(3.2)$ & $869(96.8)$ & \\
\hline \multirow[t]{4}{*}{ Education } & $\leq$ Elementary & $72(5.2)$ & $1,310(94.8)$ & 0.0353 \\
\hline & Middle & $70(5.5)$ & $1,212(94.5)$ & \\
\hline & High & $234(4.6)$ & 4,890 (95.4) & \\
\hline & $\geq$ University & $155(3.8)$ & $3,886(96.2)$ & \\
\hline \multirow[t]{7}{*}{ Occupation } & Manager, professional, and administrators & $73(4.1)$ & $1,727(95.9)$ & 0.0014 \\
\hline & Clerks & $57(4.8)$ & $1,122(95.2)$ & \\
\hline & Service and sales workers & $85(4.5)$ & $1,801(95.5)$ & \\
\hline & Skilled agricultural, forestry, and fishery workers & $32(5.3)$ & $578(94.8)$ & \\
\hline & Craft, equipment, machine operating, and assembling workers & $95(6.7)$ & $1,318(93.3)$ & \\
\hline & Elementary workers & $51(5.4)$ & $899(94.6)$ & \\
\hline & Unemployed & $121(3.8)$ & $3,042(96.2)$ & \\
\hline
\end{tabular}

*p value by chi-squared test. 
Table 5 Rate of hospitalizing for injury among those who experienced an injury

\begin{tabular}{|c|c|c|c|c|}
\hline \multirow[t]{2}{*}{ Variables } & \multirow[t]{2}{*}{ Categories } & \multicolumn{2}{|c|}{ Number (\%) } & \multirow[t]{2}{*}{ p value* } \\
\hline & & Yes & No & \\
\hline \multirow[t]{5}{*}{ Household income per year (1 million KRW) } & $<5$ & $13(5.8)$ & $212(94.2)$ & \multirow[t]{5}{*}{0.1194} \\
\hline & $5-<10$ & $38(6.5)$ & $548(93.5)$ & \\
\hline & $10-<20$ & $79(4.4)$ & $1716(95.6)$ & \\
\hline & $20-<50$ & $257(4.5)$ & $5454(95.5)$ & \\
\hline & $\geq 50$ & $117(4.3)$ & $2595(95.7)$ & \\
\hline Home value & $<50$ & $24(2.6)$ & $901(97.4)$ & \multirow[t]{5}{*}{0.065} \\
\hline \multirow[t]{4}{*}{ (1 million KRW) } & $50-<100$ & $44(3.0)$ & $1,450(97.1)$ & \\
\hline & $100-<200$ & $42(2.0)$ & $2,078(98.0)$ & \\
\hline & $200-<500$ & $38(1.8)$ & $2,046(98.2)$ & \\
\hline & $\geq 500$ & $13(1.5)$ & 885 (98.6) & \\
\hline \multirow[t]{4}{*}{ Education } & $\leq$ Elementary & $41(3.0)$ & $1,341(97.0)$ & \multirow[t]{4}{*}{0.0382} \\
\hline & Middle & $25(2.0)$ & $1,257(98.1)$ & \\
\hline & High & $126(2.5)$ & $4,998(97.5)$ & \\
\hline & $\geq$ University & $73(1.8)$ & $3,968(98.2)$ & \\
\hline \multirow[t]{7}{*}{ Occupation } & Manager, professional, and administrators & $33(1.8)$ & $1,767(98.2)$ & \multirow[t]{7}{*}{0.0006} \\
\hline & Clerks & $21(1.8)$ & $1,158(98.2)$ & \\
\hline & Service and sales workers & $31(1.6)$ & $1,855(98.4)$ & \\
\hline & Skilled agricultural, forestry, and fishery workers & $17(2.8)$ & $593(97.2)$ & \\
\hline & Craft, equipment, machine operating, and assembling workers & $55(3.9)$ & $1,358(96.1)$ & \\
\hline & Elementary workers & $20(2.1)$ & $930(97.9)$ & \\
\hline & Unemployed & $73(2.3)$ & $3,090(97.7)$ & \\
\hline
\end{tabular}

*p value by chi-squared test.

agricultural, forestry, and fishery worker' (7.7\%), 'elementary worker' (7.5\%), 'service and sales worker' (6.1\%), 'clerk' (6.7\%), and 'managerial and professional worker' (6.0\%) groups followed in that order, revealing concurrence with previous study results showing that manual labor has a higher risk of injury $[24,26,31,36]$. The unemployed had a significantly lower injury incidence than those with jobs, and their rate of seeking medical attention from an outpatient clinic or emergency room was also lower than those of the other groups. In addition, the unemployed group reported lower odds of injury than the other groups, and the group showed a particularly significant reduction in the odds of injury compared to 'skilled agricultural, forestry, and fishery worker', 'craft, equipment, machine operating, and assembling worker', and 'elementary worker' groups. This information contradicts previous studies reporting slightly but not significantly higher injury odds of 1.03 in the jobless than in those who were employed [17]. Our finding provides evidence that having a job may elevate injury risk. Our study also noted the smallest total number of injuries (5.7\%) and injury risk in all subjects in the unemployed group, but the hospital admission rate, which reflects the severity of injury, was $2.3 \%$, which was higher than the rate found in the whitecollar worker group. This is in accord with a previous study that found the risk of mortality for jobless people was 2.26 times higher than that of other groups [17]. The reason for the higher risk can be explained by reports that noted a relationship with higher incidences of violent crime [30] and suicide [25].

Socioeconomic status is known to affect injury risk through a complex process. The causes of injuries originating from socioeconomic discrimination are psychosocial factors such as stress from poverty and intentional self-inflicted injury due to the stress from inequality as a result, raising the quality of material factors such as providing a livable income and adequate housing is effective in lowering the injury risk [17]. Lower socioeconomic status may result from poor housing and transportation, higher crime rates, and underemployment [26,41-43]. In addition to physical factors, there are occupation-related factors that also affect injury incidence [44]. Socioeconomic factors are also influenced by a geographical factor that has been interpreted as the degree of accessibility to various appropriate public services such as secure public safety measures, safe road, and recreational area. Also, a prosperous town has low crime rate. It has 
Table 6 Odds ratios and $95 \%$ confidence intervals for socioeconomic factors affecting the injury experience rate by multiple logistic regression analysis

\begin{tabular}{|c|c|c|c|c|c|}
\hline Variables & Categories & Crude $\mathrm{OR}^{*}$ & $95 \% \mathrm{Cl} \dagger$ & Adjusted OR‡ & $95 \% \mathrm{Cl}$ \\
\hline \multirow{5}{*}{$\begin{array}{l}\text { Household income per year } \\
\text { (1 million KRW) }\end{array}$} & $<5$ & 1 & & 1 & \\
\hline & $5-<10$ & 0.81 & $0.49-1.35$ & 0.82 & $0.49-1.38$ \\
\hline & $10-<20$ & 0.63 & $0.39-0.99$ & 0.64 & $0.40-1.02$ \\
\hline & $20-<50$ & 0.6 & $0.39-0.93$ & 0.6 & $0.38-0.93$ \\
\hline & $\geq 50$ & 0.55 & $0.35-0.86$ & 0.54 & $0.34-0.86$ \\
\hline Home value & $<50$ & 1 & & 1 & \\
\hline \multirow[t]{4}{*}{ (1 million KRW) } & $50-<100$ & 1.08 & $0.79-1.47$ & 1.11 & $0.81-1.52$ \\
\hline & $100-<200$ & 0.9 & $0.66-1.22$ & 0.92 & $0.68-1.25$ \\
\hline & $200-<500$ & 0.86 & $0.63-1.17$ & 0.89 & $0.65-1.21$ \\
\hline & $\geq 500$ & 0.63 & $0.42-0.94$ & 0.65 & $0.43-0.96$ \\
\hline \multirow[t]{4}{*}{ Education } & $\geq$ University & 1 & & 1 & \\
\hline & $\leq$ Elementary & 1.49 & $1.18-1.88$ & 1.89 & $1.44-2.48$ \\
\hline & Middle & 1.34 & $1.04-1.71$ & 1.57 & $1.20-2.05$ \\
\hline & High & 1.23 & $1.03-1.46$ & 1.28 & $1.07-1.52$ \\
\hline \multirow[t]{7}{*}{ Occupation } & Unemployedt & 1 & & 1 & \\
\hline & Manager, professional, and administrators & 1.05 & $0.83-1.34$ & 1.05 & $0.83-1.33$ \\
\hline & Clerks & 1.19 & $0.91-1.55$ & 1.18 & $0.90-1.54$ \\
\hline & Service and sales workers & 1.07 & $0.85-1.35$ & 1.08 & $0.86-1.36$ \\
\hline & Skilled agricultural, forestry, and fishery workers & 1.38 & $1.01-1.91$ & 1.43 & $1.02-2.01$ \\
\hline & Craft, equipment, machine operating, and assembling workers & 1.96 & $1.58-2.44$ & 1.99 & $1.60-2.47$ \\
\hline & Elementary workers & 1.35 & $1.02-1.78$ & 1.38 & $1.04-1.82$ \\
\hline
\end{tabular}

*odds ratio, tconfidence interval.

‡: adjusted for age, sex, and marital status.

been suggested that the low crime rate is due to limiting strangers from accessing the town and encouraging good behavior among members of the community, and these positive activities have some protective value in preventing injury [11]. Those with a low socioeconomic level are likely to neglect the fact that injury is preventable, and this inattention may function as a factor that leads to the potential for injury [45]. A parent's socioeconomic status is also an important factor in injury risk for children. Although the effect varies by the age and sex of a child, a parent's efforts in providing their children with appropriate education, housing, and injury preventative measures are presently considered imperative for reducing injury risk [46-52].

There present some limitations for this study. This study's variables are obtained from a questionnaire and interview, and it is possible that the study is biased with recall bias from subjects. During the survey, surveyors tried to visit each subjects to obtain data directly. Data was not available from those who were admitted to a hospital or had deceased, and data from these subjects may be left out for interpretation. However, possibility of selection bias that may underestimates injury incidence is low, because fourth KNHANES was carried out as an individualized interview to each subject without knowing subjects' trauma histories. Future studies further need more in-depth interviews and objective reviews on data to improve the analysis, and it is also considered that supplementing questions related injury, training surveyors, standardization of indicators, and checking reliability and validity of indicators are necessary to refine the outcomes in future studies. In this study, only a person's income was taken in for socioeconomic evaluation, but the future studies need to consider obtaining more information on a person's asset including car and financial asset for multidimensional interpretation. Lastly, there present a limitation to examine causal relationship between socioeconomic state and injury in this study, because it was a cross-section study. In order to investigate the causal relationship, a prospective cohort study is required.

\section{Conclusions}

Despite these limitations, by using the answers to the injury-related questions of the fourth KNHANES, this study was able to confirm the differences in injury 
incidence among various socioeconomic levels represented by differing education levels, incomes, home values, and types of occupations. Furthermore, the authors investigated the relationship between socioeconomic status and injury and confirmed that lower income and education levels were associated with a statistically significant increase in the odds of injury. In addition, the groups with jobs had a higher risk of injury than the unemployed group, and manual laborers had significantly elevated injury risk. Through this study, it was determined that many injuries have preventable aspects, and vulnerable socioeconomic groups were identified as being an important focus for injury risk management. Information on the frequency of injury and conditions inciting injury enables the recognition of injury severity and characteristics and also provides a basis for the development of injury prevention and management policy [2]. A gradual multistage approach to injury-related problems and the selection of groups who need priority intervention are necessary to reduce injury incidence [7]. Developing interventions will require identifying the present state of injury, followed by recognizing causes and factors that are associated with injury. This information can be used to work out a basis for the distribution of available resources to prevent and manage injuries. We believe that the results of this study can be used as a reference for selection of a group in Korea that requires priority in receiving intervention.

\section{Competing interests}

The authors declared that they have no competing interests.

\section{Authors' contributions}

SKK and SBK designed a research method, analyzed the data and drafted the manuscript. HK, KL, HTK, and SSO participated in research process and collected data. All authors read and approved the final manuscript.

\section{Acknowledgements}

This work was carried out with the support of "Cooperative Research Program for Agriculture Science \& Technology Development

(PJ0064222012)" Rural Development Administration, Republic of Korea.

\section{Author details}

'Department of Occupational and Environmental Medicine, Wonju Severance Christian's Hospital, Yonsei University, Wonju, Korea. ${ }^{2}$ National Academy of Agricultural Science (NAAS), Rural Development Administration (RDA), Seoul, Suwon, Korea.

Received: 1 November 2012 Accepted: 12 November 2013 Published: 3 January 2014

\section{References}

1. Holder Y, Peden M, Krug E, Lund J, Gururaj G, Kobusingye O (Eds): Injury Surveillance Guidelines. Geneva: World Health Organization; 2001.

2. Peden M, McGee K, Krug E (Eds): Injury: A Leading Cause of the Global Burden of Disease, 2000. Geneva: World Health Organization; 2002.

3. Rivara FP, Grossman DC, Cummings P: Injury Prevention. N Engl J Med 1997, 337:613-618

4. Peden M, McGee K, Sharma G: The Injury Chart Book: A Graphical Overview of the Global Burden of Injuries. Geneva: World Health Organization; 2002.

5. Sleet DA: Injury prevention and public health. Ital J Public Health 2012, 7(2):3-5.
6. Organisation for Economic Co-operation and Development: OECD Health Data 2007: Statistics and Indicators for 30 Countries. Paris: Organisation for Economic Co-operation and Development; 2007.

7. Lee E, Lee JS, Kim Y, Park KH, Eun SJ, Suh SK, Kim Yl: Patterns of Unintentional Domestic Injuries in Korea. J Prev Med Pub Health 2010, 43:84-92.

8. Vyrostek SB, Annest JL, Ryan GW: Surveillance for fatal and nonfatal injuries-United States, 2001. MMWR Surveill Summ 2004, 53:1-57.

9. Heinrich $\mathrm{H}$ : Industrial Accident Prevention. 5th edition. New York: McGraw-Hill; 1980:3-80.

10. Dembe $A E$, Erickson $J B$, Delbos R: Predictors of work-related injuries and illnesses: national survey findings. J Occup Environ Hyg 2004, 1:542-550.

11. Swaen GM, van Amelsvoort LP, Bultmann U, Slangen JJ, Kant IJ: Psychosocial work characteristics as risk factors for being injured in an occupational accident. J Occup Environ Med 2004, 46:521-527.

12. Nakata A, Ikeda T, Takahashi M, Haratani T, Hojou M, Fujioka Y, Swanson NG, Araki S: Impact of psychosocial job stress on non-fatal occupational injuries in small and medium-sized manufacturing enterprises. Am J Ind Med 2006, 49:658-669.

13. Potter BK, Speechley KN, Koval JJ, Gutmanis IA, Campbell MK, Manuel D: Socioeconomic status and non-fatal injuries among Canadian adolescents: variations across SES and injury measures. BMC Public Health 2005, 5:132.

14. Haddon W Jr: Options for the prevention of motor vehicle crash injury. Isr J Med Sci 1980, 16:45-65.

15. Pickett KE, Pearl M: Multilevel analyses of neighbourhood socioeconomic context and health outcomes: a critical review. J Epidemiol Community Health 2001, 55:111-122.

16. Yen $I H$, Syme SL: The social environment and health: a discussion of the epidemiologic literature. Annu Rev Public Health 1999, 20:287-308.

17. Cubbin C, Smith GS: Socioeconomic inequalities in injury: critical issues in design and analysis. Annu Rev Public Health 2002, 23:349-375.

18. Lee JS, Kim SD, Lee DK, Lee JS: The incidence rates and risk factor of mild injury for two weeks: Using Korea National Health and Nutrition Examination Survey 2001. J Prev Med Public Health 2008, 41:279-286.

19. Korea Centers for Disease Control and Prevention: Guide to the utilization of the data from the forth Korea National Health and Nutrition Examination Survey. Seoul: Korea Centers for Disease Control and Prevention; 2010.

20. Jung DY, Kim HC, Leem JH, Park SG, Lee DH, Lee SJ, Kim GW: Estimated occupational injury rate and work related factors based on data from the fourth Korea national health and nutrition examination survey. Korean J Occup Environ Med 2011, 23:149-163.

21. Occupational Safety and Health Research Institute: A Study on the Cause of Stagnation of Korea Occupational injuries and Countermeasures. Incheon: Occupational Safety and Health Research Institute; 2010.

22. Hokstad P, Steiro T: Overall strategy for risk evaluation and priority setting of risk regulations. Reliability Eng Syst Safe 2006, 91:100-111.

23. Baker SP, Whitfield RA, O'Neill B: Geographic variations in mortality from motor vehicle crashes. N Engl J Med 1987, 316:1384-1387.

24. Burnley $\mathrm{IH}$ : Socioeconomic and spatial differentials in mortality and means of committing suicide in New South Wales, Australia, 1985-91. Soc Sci Med 1995, 41:687-698.

25. Crawford MJ, Prince M: Increasing rates of suicide in young men in England during the 1980s: the importance of social context. Soc Sci Med 1999, 49:1419-1423.

26. Cubbin C, LeClere FB, Smith GS: Socioeconomic status and injury mortality: individual and neighbourhood determinants. J Epidemiol Community Health 2000, 54:517-524.

27. Dayal H, Goldberg-Alberts R, Kinman J, Ramos J, Sharrar R, Shapiro S: Patterns of mortality from selected causes in an urban population. J Chronic Dis 1986, 39:877-888.

28. Dougherty G, Pless IB, Wilkins R: Social class and the occurrence of traffic injuries and deaths in urban children. Can J Public Health 1990, 81:204-209.

29. Hussey JM: The effects of race, socioeconomic status, and household structure on injury mortality in children and young adults. Matern Child Health J 1997, 1:217-227.

30. Kyriacou DN, Hutson HR, Anglin D, Peek-Asa C, Kraus JF: The relationship between socioeconomic factors and gang violence in the city of Los Angeles. J Trauma-Inj Infect Crit Care 1999, 46:334-339.

31. Loomis DP: Occupation, industry, and fatal motor vehicle crashes in 20 states, 1986-1987. Am J Public Health 1991, 81:733-735.

32. Mierley MC, Baker SP: Fatal house fires in an urban population. JAMA 1983, 249:1466-1468. 
33. Pearce NE, Davis PB, Smith AH, Foster FH: Mortality and social class in New Zealand II: male mortality by major disease groupings. N Z Med J 1983, 96:711-716

34. Wise PH, Kotelchuck M, Wilson ML, Mills M: Racial and socioeconomic disparities in childhood mortality in Boston. N Engl J Med 1985, 313:360-366.

35. Fife D, Faich G, Hollinshead W, Boynton W: Incidence and outcome of hospital-treated head injury in Rhode Island. Am J Public Health 1986, 76:773-778.

36. Wagener DK, Winn DW: Injuries in working populations: black-white differences. Am J Public Health 1991, 81:1408-1414.

37. Adler NE, Boyce T, Chesney MA, Cohen S, Folkman S, Kahn RL, Syme SL: Socioeconomic status and health. The challenge of the gradient. Am Psychol 1994, 49:15-24.

38. Marmot MG, Stansfeld S, Patel C, North F, Head J, White I, Brunner E, Feeney A, Smith GD: Health inequalities among British civil servants: the Whitehall II study. Lancet 1991, 337:1387-1393.

39. Chichester BM, Gregan JA, Anderson DP, Kerr JM: Associations between road traffic accidents and socio-economic deprivation on Scotland's west coast. Scott Med J 1998, 43:135-138.

40. Helmkamp JC, Bone CM: Hospitalizations for accidents and injuries in the US Navy: environmental and occupational factors. J Occup Med 1986, 28:269-275

41. Baker SP: Determinants of injury and opportunities for intervention. Am J Epidemiol 1975, 101:98-102.

42. Rivara FP: Developmental and behavioral issues in childhood injury prevention. J Dev Behav Pediatr 1995, 16:362-370.

43. Glik DC, Greaves PE, Kronenfeld JJ, Jackson KL: Safety hazards in households with young children. J Pediatr Psychol 1993, 18:115-131.

44. Shannon HS, Robson LS, Sale JE: Creating safer and healthier workplaces: role of organizational factors and job characteristics. Am J Ind Med 2001, 40:319-334.

45. Girasek DC: Public beliefs about the preventability of unintentional injury deaths. Accid Anal Prev 2001, 33:455-465.

46. West $P$ : Health inequalities in the early years: is there equalisation in youth? Soc Sci Med 1997, 44:833-858.

47. Howe LD, Huttly SRA, Abramsky T: Risk factors for injuries in young children in four developing countries: the young lives study. Trop Med Int Health 2006, 11:1557-1566.

48. Gilbride SJ, Wild C, Wilson DR, Svenson LW, Spady DW: Socio-economic status and types of childhood injury in Alberta: a population based study. BMC Pediatr 2006, 6:30

49. Nathens AB, Neff MJ, Goss CH, Maier RV, Rivara FP: Effect of an older sibling and birth interval on the risk of childhood injury. Inj Prev 2000, 6:219-222.

50. Reading R, Langford IH, Haynes R, Lovett A: Accidents to preschool children: Comparing family and neighbourhood risk factors. Soc Sci Med 1999, 48:321-330.

51. Scholer SJ, Hickson GB, Ray WA: Sociodemographic factors identify us infants at high risk of injury mortality. Pediatrics 1999, 103:1183-1188.

52. Scholer SJ, Mitchel EF Jr, Ray WA: Predictors of injury mortality in early childhood. Pediatrics 1997, 100:342-347.

doi:10.1186/2052-4374-26-1

Cite this article as: Kim et al: The Relationship between Injury and Socioeconomic Status in Reference to the Fourth Korean National Health and Nutrition Examination Survey. Annals of Occupational and Environmental Medicine 2014 26:1.

\section{Submit your next manuscript to BioMed Central and take full advantage of:}

- Convenient online submission

- Thorough peer review

- No space constraints or color figure charges

- Immediate publication on acceptance

- Inclusion in PubMed, CAS, Scopus and Google Scholar

- Research which is freely available for redistribution 